\title{
DESEMPENHO DA PRODUTIVIDADE DE ESPIGAS DE MILHO VERDE SOB DIFERENTES REGIMES HÍDRICOS
}

\author{
FÁBIO NUNES DO NASCIMENTO ${ }^{1}$, EDSON ALVES BASTOS ${ }^{2}$, MILTON JOSÉ CARDOSO $^{2}$, \\ ADERSON SOARES DE ANDRADE JÚNIOR ${ }^{2}$ e HERBERT MOREIRA RAMOS ${ }^{3}$
}

${ }^{1}$ IFPI, Valença,PI, Brasil,fabio.nunes@ifpi.edu.br;

${ }^{2}$ Embrapa Meio-Norte, Teresina, PI, Brasil,edson.bastos@embrapa.br,milton.cardoso@embrapa.br,aderson.andrade@embrapa.br; ${ }^{3} P P G A$, Teresina,PI, moreiraramoss@hotmail.com

Revista Brasileira de Milho e Sorgo, v.16, n.1, p. 94-108, 2017

RESUMO- O cultivo do milho verde irrigado está em expansão na região Nordeste do Brasil e há uma forte demanda. Entretanto, há necessidade de informações técnica e cientifica sobre o manejo de irrigação adequado. O objetivo deste trabalho foi avaliar o efeito de diferentes lâminas de irrigação sobre os componentes de produção e a produtividade de espigas verde do híbrido duplo comercial AG 1051, nas condições edafoclimáticas de Teresina, Piauí. Os tratamentos, dispostos em blocos ao acaso com quatro repetições, constaram de cinco lâminas de irrigação: 165,51, 208,85, 255,32, 304,39 e 340,57 mm. Durante a condução do experimento, a precipitação não ultrapassou $17 \mathrm{~mm}$, a umidade relativa do ar manteve-se na faixa de $62 \%$ a $68 \%$ e as temperaturas do ar mínimas, médias e máximas apresentaram uma variação entre $22{ }^{\circ} \mathrm{C}$ e $35{ }^{\circ} \mathrm{C}$. Os resultados de produtividade de espiga verde empalhada e despalhada foram de $13.453,13$ $\mathrm{kg} \mathrm{ha}^{-1}$ e 8.465,62 $\mathrm{kg} \mathrm{ha}^{-1}$, respectivamente, obtidos com a lâmina de irrigação de 340,57 mm. Os componentes de produção comprimento e diâmetro de espiga empalhada e despalhada, média de grãos por espiga e número de grãos por fileiras foram os que melhor contribuíram para esses resultados.

Palavras-chave: aspersão, espiga comercial, híbrido, irrigação.

\section{PRODUCTIVITY OF GREEN CORN UNDER DIFFERENT WATER MANAGEMENT SYSTEMS}

\begin{abstract}
The cultivation of irrigated green corn is growing in the Northeast region of Brazil and there is a strong demand. However, there is a need for technical and scientific information on the proper management of irrigation. The aim of this study was to evaluate the effect of different irrigation levels on the yield components and productivity of green ears double hybrid commercial AG 1051, at conditions of Teresina, Piauí, Brazil. The treatments were arranged in a randomized block design with four replications, consisted of five irrigation 165.51, 208.85, 255.32, 304.39 and $340.57 \mathrm{~mm}$. During the experiment, rainfall did not exceed $17 \mathrm{~mm}$, relative humidity remained in the range of $62 \%$ to $68 \%$ and the minimum, medium and maximum temperatures showed a variation between $22{ }^{\circ} \mathrm{C}$ and $35^{\circ} \mathrm{C}$. Productivity results of green spike with and without straw were $13,453.13 \mathrm{~kg} \mathrm{ha}^{-1}$ and $8,465.62 \mathrm{~kg} \mathrm{ha}^{-1}$ respectively obtained with the irrigation depth of $340,57 \mathrm{~mm}$. The components of production length and diameter of spike with and without straw, average grains per spike and number of grains per row were the best that contributed to these results.
\end{abstract}

Keywords: aspersion, commercial ear, hybrid, irrigation. 
O plantio do milho verde é uma tradição no Brasil. Apesar do número reduzido de cultivares encontradas no mercado de sementes para esse fim, trata-se de uma atividade promissora, concentrando-se em pequenas e médias propriedades com áreas entre 1 e 10 ha.

Para atender a demanda crescente, do mercado por melhores espigas de milho verde, se faz necessário aperfeiçoar o sistema de produção de milho visando o consumo verde, buscando melhorias na produção e espigas mais em conformidade com as exigências do mercado. Diante do exposto, a irrigação torna-se então uma alternativa interessante, porque possibilita o plantio durante todo o ano.

Figueiredo et al. (2008) consideram que o manejo adequado da irrigação supõe o uso criterioso do recurso hídrico disponível para se atingir um determinado objetivo, como alcançar alta produtividade das culturas com o uso eficiente da água, da energia e de outros fatores de produção.

A partir da adoção de estratégias de irrigação é importante conhecer o efeito do déficit hídrico nos estágios de desenvolvimento da planta. O cultivo do milho nas primeiras fases de desenvolvimento é limitado pela deficiência hídrica, principalmente sob lâminas inferiores a 80\% da ETc (Brito et al., 2013).

O estresse hídrico é um dos principais fatores limitante à produtividade de grãos e espigas para o consumo verde em ambientes tropicais e subtropicais (Fornasieri Filho, 2007). Por sua vez, Bergamaschi et al. (2004) constataram que o número de grãos por espiga e espigas por planta são os componentes da produção mais afetados pelo déficit hídrico, quando este ocorre na fase de pendoamento até a fase do início do enchimento dos grãos.

Rivera-Hernández et al. (2010) verificaram que há decréscimos no comprimento de espigas com estresse hídrico, e Bergamaschi et al. (2006) observaram uma redução linear, com maior impacto na produtividade de grãos à medida que se elevou o déficit hídrico, na fase de florescimento.

A altura de planta é um parâmetro que pode ser afetado tanto pela densidade de plantas como pelo déficit hídrico. Quando intenso, este provoca o fechamento dos estômatos, reduz a transpiração, também a fotossíntese e, consequentemente, a produção de fotoassimilados e o crescimento das plantas.

$\mathrm{O}$ diâmetro de colmo e a produtividade de espigas despalhadas expressaram maiores valores em função do maior tempo de irrigação e com maior oferta de água (Biscaro et al., 2008). Os resultados de Oktem (2008) também revelam um aumento progressivo de produtividade de espigas verdes em função da irrigação.

Nesse contexto, a pesquisa teve como objetivo avaliar o efeito de diferentes lâminas de irrigação sobre os componentes de produção e a produtividade de espigas para o consumo verde.

\section{Material e Métodos}

O experimento foi conduzido no campo Experimental da Embrapa Meio-Norte, situado nas coordenadas geográficas de $5^{\circ} 05^{\prime} \mathrm{S}, 42^{\circ} 29^{\prime} \mathrm{W}$ e $72 \mathrm{~m}$ de altitude, no período de setembro a novembro de 2010 , em Teresina-PI. O clima da região, segundo classificação climática de Thornthwaite e Mather (1955), é C1sA'a', caracterizado como subúmido seco, megatérmico, com excedente hídrico moderado no verão e uma concentração de $32,2 \%$ da evapotranspiração potencial no trimestre setembro-outubro-novembro (Bastos \& Andrade Júnior, 2014).

O solo da área experimental é um Argissolo Vermelho Amarelo eutrófico (Santos et al., 2006), 
cujas características químicas e físico-hídricas encontram-se nas Tabelas 1 e 2 , respectivamente.

O preparo do solo foi realizado de forma convencional, com uma aração e duas gradagens. A semeadura ocorreu de forma manual, com auxílio de uma matraca, disposta no espaçamento de $0,80 \mathrm{~m} \mathrm{x}$ $0,25 \mathrm{~m}$.

Utilizou-se a cultivar de milho híbrido comercial AG1051, de ciclo semiprecoce, grão amarelo e dentado, resistência ao acamamento, desenvolvido para produção de grãos, silagem e milho verde.

A adubação utilizada na semeadura foi de 40 $\mathrm{kg}$ de $\mathrm{N} \mathrm{ha}^{-1}, 80 \mathrm{~kg}$ de $\mathrm{P}_{2} \mathrm{O}_{5}$ ha $^{-1}$ e $35 \mathrm{~kg}$ de $\mathrm{K}_{2} \mathrm{O}$ ha 1. Foram feitas duas adubações de cobertura, sendo a primeira por ocasião da sexta folha completamente desenvolvida, com $40 \mathrm{~kg}$ de $\mathrm{N}^{-1}$ mais $35 \mathrm{~kg}$ de $\mathrm{K}_{2} \mathrm{O} \mathrm{ha}^{-1}$, e a segunda, com $40 \mathrm{~kg}$ de $\mathrm{N} \mathrm{ha}^{-1}$ quando as plantas estavam com oito folhas completamente desenvolvidas. Os fertilizantes utilizados em cobertura foram o sulfato de amônia como fonte de $\mathrm{N}$, por causa da sua menor volatilização, e cloreto de potássio como fonte de $\mathrm{K}_{2} \mathrm{O}$. Efetuou-se o desbaste quinze dias após a semeadura (DAS), deixando uma planta por cova para um estande de 50.000 plantas por hectare.

No controle de plantas daninhas, foram feitas capinas aos 12 DAS e 22 DAS, com enxada e também tração animal. Foram utilizados os inseticidas Lufenuron $\left(1 \mathrm{ml} \mathrm{L}^{-1}\right)$ e Lambdacyhalothrin (1 ml $\left.\mathrm{L}^{-1}\right)$. As aplicações ocorreram aos 16 DAS e $38 \mathrm{DAS}$, objetivando o controle da lagarta-do-cartucho (Spodoptera frugiperda, Smith). A colheita foi realizada de forma manual aos 68 DAS.

O delineamento experimental foi de blocos ao acaso e quatro repetições, com os tratamentos dispos-

Tabela 1. Características químicas do solo da área experimental. Teresina- PI (2010).

\begin{tabular}{lllllllllll}
\hline $\begin{array}{l}\text { Prof. } \\
(\mathrm{m})\end{array}$ & $\mathrm{MO}$ & $\mathrm{pH}$ & $\mathrm{P}$ & $\mathrm{K}^{+}$ & $\mathrm{Ca}^{2+}$ & $\mathrm{Mg}^{2+}$ & $\mathrm{Na}^{+}$ & $\mathrm{H}^{+}+\mathrm{Al}^{3+}$ & $\mathrm{CTC}$ & $\mathrm{V}$ \\
\hline $0,00-0,20$ & 4,20 & 5,78 & 33,80 & 1,7 & 14,7 & 7,6 & 0,1 & 21,5 & 45,6 & 52,91 \\
$0,20-0,40$ & 4,15 & 5,37 & 14,10 & 1,3 & 17,9 & 5,8 & 0,1 & 33,8 & 58,9 & 42,60 \\
\hline
\end{tabular}

Fonte: Laboratório de Solos da Embrapa Meio-Norte.

Tabela 2. Características físico-hídricas do solo da área experimental. Teresina-PI (2010).

\begin{tabular}{lcl}
\hline \multirow{2}{*}{ Características } & \multicolumn{2}{c}{ Camadas do solo $(\mathrm{m})$} \\
\cline { 2 - 3 } & $0,00-0,20$ & $0,20-0,40$ \\
\hline Densidade do solo $\left(\mathrm{Mg} \mathrm{m}^{-3}\right)$ & 1,23 & 1,40 \\
Areia grossa $\left(\mathrm{g} \mathrm{kg}^{-1}\right)$ & 784 & 433 \\
Areia fina $\left(\mathrm{g} \mathrm{kg}^{-1}\right)$ & 95 & 191 \\
Silte $\left(\mathrm{g} \mathrm{kg}^{-1}\right)$ & 35 & 170 \\
Argila $\left(\mathrm{g} \mathrm{kg}^{-1}\right)$ & 86 & 206 \\
$\mathrm{CC}\left(\mathrm{cm}^{3} \mathrm{~cm}^{-3}\right)$ & 0,22 & 0,22 \\
PM $\left(\mathrm{cm}^{3} \mathrm{~cm}^{-3}\right)$ & 0,09 & 0,11 \\
\hline
\end{tabular}

Fonte: Laboratório de Solos da Embrapa Meio-Norte. CC: capacidade de campo PM: ponto de murcha. 
tos em faixas. Os tratamentos constaram de cinco lâminas de irrigação, considerando as seguintes variações da evapotranspiração de referência (ETo): $25 \%$ da ETo; $50 \%$ da ETo; $75 \%$ da ETo; $100 \%$ da ETo e $125 \%$ da ETo. As parcelas foram constituídas de seis fileiras de 7,0 $\mathrm{m}$ de comprimento espaçadas de $0,80 \mathrm{~m}$ e 0,25 m dentro das fileiras, mantendo-se uma planta por cova, após o desbaste. Como área útil, consideraram-se as quatros fileiras centrais constituídas de uma área de 3,20 m x 5,0 m, totalizando $16,0 \mathrm{~m}^{2}$.

Utilizou-se um sistema de irrigação por aspersão convencional fixo, com aspersores de impacto com bocais de 4,4 mm x 3,2 mm, vazão de 1,59 $\mathrm{m}^{3} \mathrm{~h}^{-1}$ a uma pressão de serviço de $3,010^{6} \mathrm{~Pa}$, espaçados de $12 \mathrm{~m} \mathrm{x} 12 \mathrm{~m}$. Na condução do experimento, determinaram-se os valores médios das lâminas de irrigação aplicadas por faixa, através de coletores instalados dentro das parcelas, cujo conteúdo era medido por meio de uma proveta graduada em milímetros após cada irrigação.

O manejo de irrigação baseou-se nos valores da evapotranspiração de referência (ETo), estimados pelo modelo de Penman-Monteith (Allen et al., 1998), sendo as lâminas determinadas em função dos tratamentos, cujos dados climáticos foram obtidos em uma estação meteorológica automática, situada próxima da área experimental.

O monitoramento do teor de água no solo foi executado por meio de uma sonda de capacitância (FDR) modelo Diviner 2000®, que se constitui em um equipamento portátil, que utiliza o princípio da capacitância elétrica e monitora o teor de água no solo a cada $0,10 \mathrm{~m}$ em até $1 \mathrm{~m}$ de profundidade. As leituras de frequência relativa (FR) foram feitas sempre antes e 24 horas após a aplicação das lâminas de irrigação. Para tanto, foram instalados 15 tubos de acesso em PVC, com 1,5 m de comprimento, na direção perpen- dicular à aplicação das lâminas de irrigação sendo três tubos em cada uma das cinco faixas.

Avaliaram-se: os diâmetros e comprimentos das espigas empalhadas e despalhadas, determinados de dez espigas colhidas aleatoriamente na parcela, utilizando-se de um paquímetro manual e de uma régua milimétrica. A produtividade das espigas empalhadas por hectare (PEEHA) e das espigas despalhadas por hectare (PEDHA) foram obtidos pela colheita feita na área útil $\left(16 \mathrm{~m}^{2}\right)$ de todas as parcelas, sendo posteriormente pesadas com auxílio de uma balança de capacidade de $50 \mathrm{~kg}$. Também se avaliaram as médias de grãos por espiga (MGE) e o número de grãos por fileira (NGF). A média de fileiras de grãos por espiga (MFE) foi determinada em dez espigas verdes tomadas ao acaso nas parcelas. O número de espiga por hectare foi obtido pela transformação dos dados originais pela sua raiz quadrada, para corrigir a variância (RQNEHA). O índice de espiga (IE) foi determinado pela razão entre número de espigas e o estande final de plantas na área útil.

Os dados obtidos foram submetidos à análise de variância pelo teste $\mathrm{F}$, de acordo com o delineamento experimental adotado, ao nível 1\% e 5\% de probabilidade. A fim de verificar a influência das lâminas de irrigação sobre a produtividade de milho verde, estimou-se uma função de resposta por meio de uma regressão polinomial, usando-se o programa computacional estatístico do SAS.

\section{Resultados e Discussão}

Os dados climáticos decendiais de umidade relativa do ar, temperaturas do ar máximas, médias e mínimas e também precipitação durante o período de condução da pesquisa são apresentados nas Figuras 1A e $1 \mathrm{~B}$. 
Os dados de umidade relativa do ar mostram que os valores médios se mantiveram na faixa de $61,92 \%$ a $67,65 \%$ durante os decêndios da condução do experimento. Já as temperaturas mínimas do ar apresentaram uma variação de $22{ }^{\circ} \mathrm{C}$ a $23{ }^{\circ} \mathrm{C}$, as médias de $28{ }^{\circ} \mathrm{C}$ a $29{ }^{\circ} \mathrm{C}$ e as máximas entre $35^{\circ} \mathrm{C}$ a $37{ }^{\circ} \mathrm{C}$ no decorrer dos decêndios (Figuras 1A e 1B). O total de precipitação durante a condução do ensaio não ultrapassou $17 \mathrm{~mm}$, distribuídos nos três últimos decêndios, com valores de 9,3 mm, 5,9 mm e 1,0 mm, respectivamente (Figura 1B).

Os valores totais das lâminas de irrigação, obtidos com percentuais da evapotranspiração de referência (ETo) (25\% da ETo, $50 \%$ da ETo, $75 \%$ da ETo, $100 \%$ da ETo e $125 \%$ da ETo) foram: 165,51, 208,85, 255,32, 304,39 e 340,57 mm, respectivamente. Na Figura 2, pode-se observar a variação média do teor de água no solo até $0,50 \mathrm{~m}$ de profundidade.
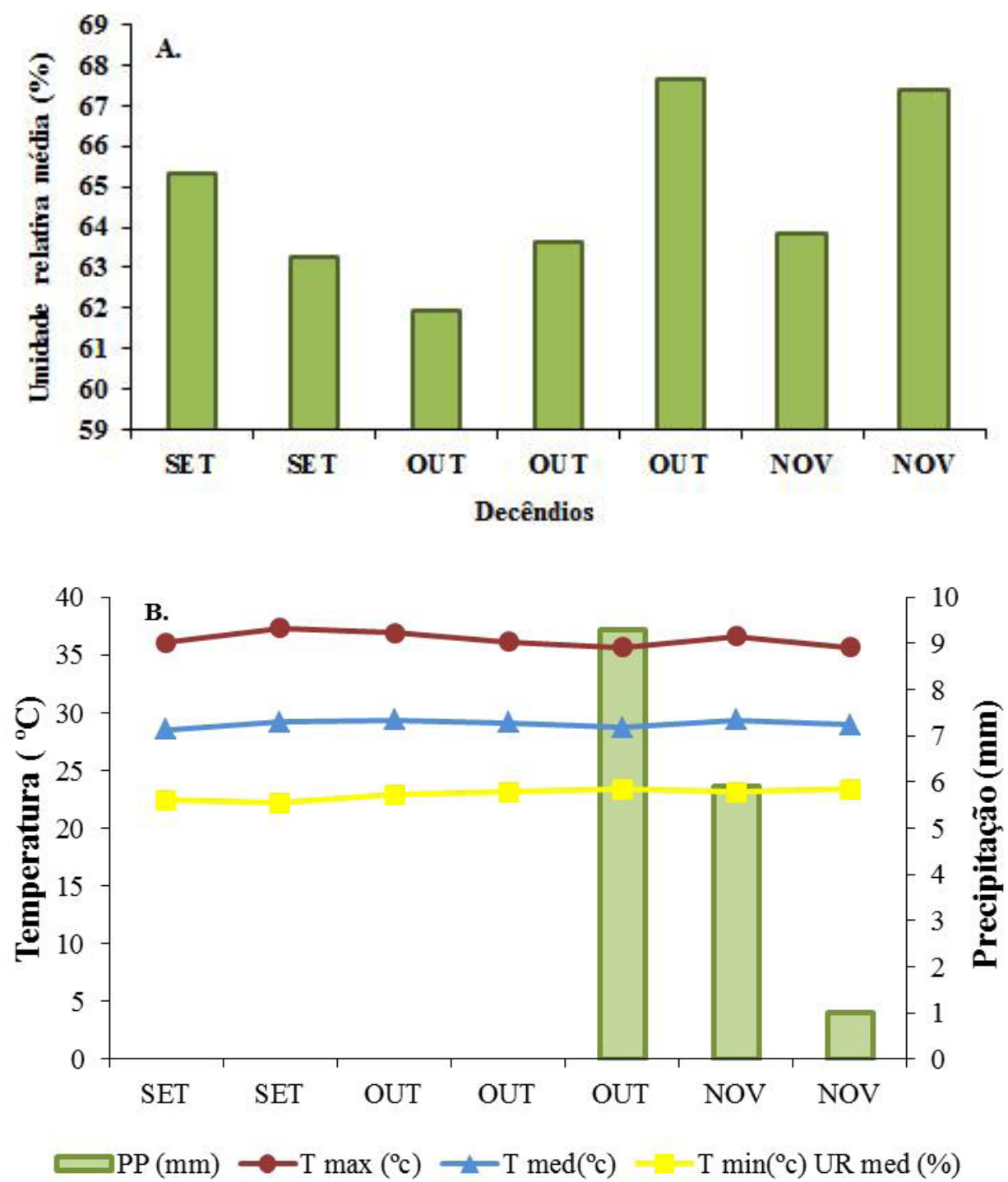

Figura 1. Valores de umidade relativa média (A), temperatura do ar máxima, média e mínima e precipitação (B) para os decêndios dos meses de setembro, outubro e novembro de 2010, Teresina- PI. 
Os valores indicam que houve um gradiente decrescente do teor de água no solo, com o tratamento de maior lâmina permanecendo, a maioria parte do ciclo da cultura, próximo à capacidade de campo $(22 \%)$ e o de menor lâmina, próximo ao ponto de murcha permanente (9\%) (Figura 2). Quanto aos tratamentos intermediários $(100 \% \mathrm{e}$ $75 \%$ da ETo), o teor de água no solo permaneceu próximo aos limites de água disponível para cultura do milho, que, segundo Doorenbos e Kassam (1994), é de 50\%.

Observando a Figura 3, ao aplicar as maiores lâminas (125\% da ETo e 100\% da ETo), os níveis de disponibilidade de água mantiveram-se acima de $80 \%$ em todo o perfil do solo $(0,00 \mathrm{~m}$ a $0,50 \mathrm{~m})$. Já as lâminas $75 \%$ da ETo e $50 \%$ da ETo apresentaram comportamentos semelhantes entre si em quase todo o perfil, estabelecendo-se entre $60 \%$ e $80 \%$ da dis- ponibilidade de água. Quanto à aplicação da menor lâmina de irrigação ( $25 \%$ da ETo), apresentou uma disponibilidade de água com valores entre $40 \%$ e $49 \%$ em todo o perfil, constatando-se um maior déficit hídrico neste tratamento. Fornasieri Filho (2007) relata que, quando ocorre déficit hídrico até $0,30 \mathrm{~m}$ de profundidade, a planta de milho fica ainda mais vulnerável, uma vez que a maior parte das raízes se encontra nesta profundidade.

Nos resultados obtidos para as características relacionadas ao crescimento da planta, houve efeito $(\mathrm{p}<0,01)$ apenas para altura de planta (Tabela 3). Esses valores foram 224,77, 215,45, 194,24, 183,20 e $181,01 \mathrm{~cm}$, respectivamente, comprovando o efeito negativo do déficit hídrico sobre esta variável, com consequente fechamento dos estômatos, reduzindo a transpiração, a fotossíntese, a produção de fotoassimilados e o crescimento da planta.

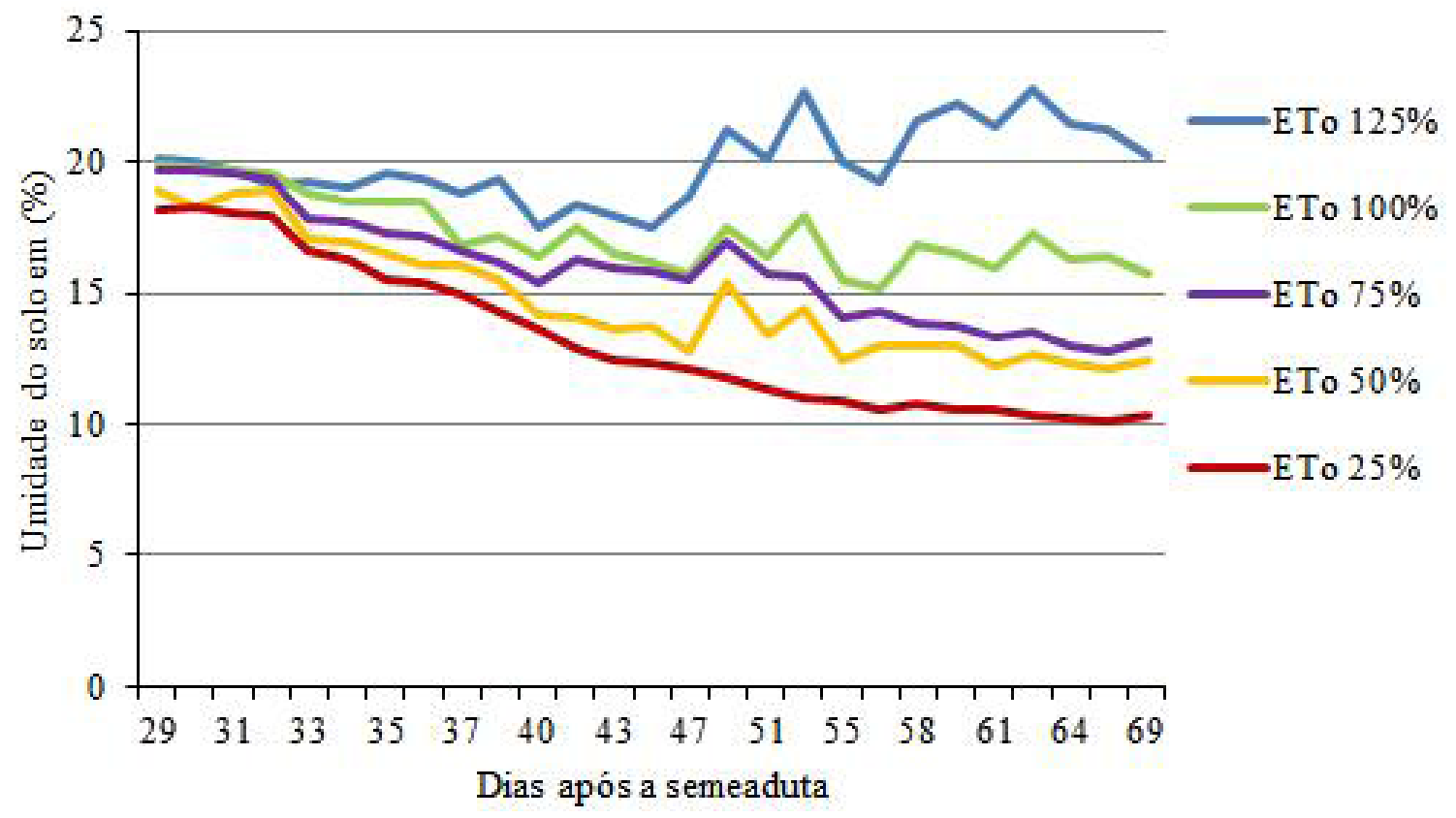

Figura 2. Variação da umidade média do solo a uma profundidade de $0,50 \mathrm{~m}$, durante o ciclo do milho verde em função das lâminas de água aplicadas, de acordo com percentuais da evapotranspiração de referência (ETo). 


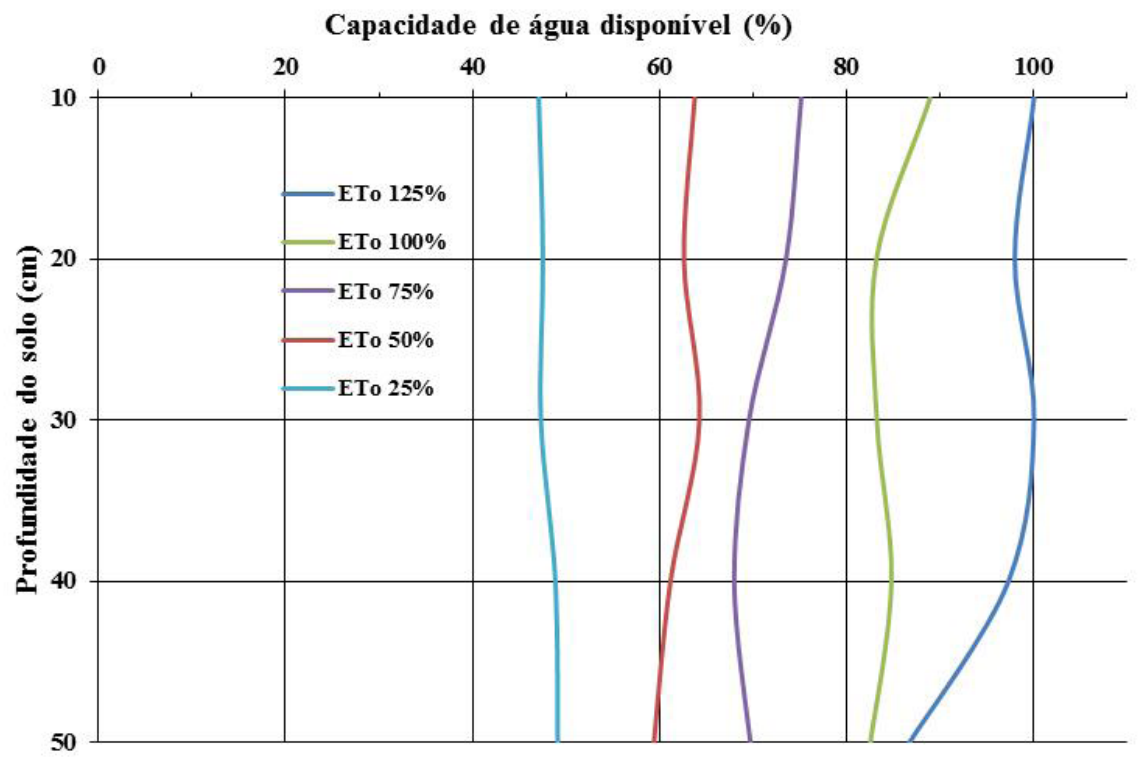

Figura 3. Capacidade de água disponível para o milho verde após a diferenciação das lâminas de irrigação de acordo com percentuais da evapotranspiração de referência (ETo).

Tabela 3. Resumo do uso da regressão na análise de variância correspondente à altura de planta (APL). Teresina-PI, 2010.

\begin{tabular}{lll}
\hline & \multicolumn{2}{c}{ Quadrado Médio } \\
\cline { 2 - 3 } FV & G.L & APL \\
\hline L' & 1 & $4902,13^{* *}$ \\
Desv.Reg & 3 & $143,4359^{\text {ns }}$ \\
BL & 3 & 140,0432 \\
Resíduo & 10 & 89,5193 \\
\hline CV $(\%)$ & \multicolumn{3}{c}{4,69} \\
\hline ns, ** = não significativo e significativo $1 \%$, pelo Teste F.
\end{tabular}

A Figura 4, que representa a altura de planta, apresentou uma resposta linear em função dos tratamentos adotados, com um incremento de $0,264 \mathrm{~cm}$ para cada milímetro de lâmina de irrigação aplicada.

Fornasieri Filho (2007) reporta que a redução da altura da planta pode ser explicada pela associação entre o sistema radicular e a parte aérea $(A / R)$ variarem em função dos fatores ambientais nas diversas fases de desenvolvimento da planta. Sob deficiência hídrica, há uma redução no valor de $\mathrm{A} / \mathrm{R}$, por causa da inibição do crescimento da parte aérea e do maior crescimento das raízes.

Resultados encontrados por Calonego et al. (2011), em estudo realizado em condições de sequeiro, apresentaram uma altura de planta para o híbrido AG 1051 entre 210 e $227 \mathrm{~cm}$, semelhantes a altura obtida para as maiores lâminas neste trabalho. Resultado semelhante para altura de planta foi encontrado por Silva et al. (2014) em condições pluviométricas de sequeiro, com médias de $212 \mathrm{~cm}$ com o híbrido AS32 e $216 \mathrm{~cm}$ com o híbrido AS 1540. Albuquerque et al. (2008), também em regime de sequeiro, relataram alturas médias de plantas de 181, 162 e $172 \mathrm{~cm}$, corroborando com os resultados das menores lâminas encontradas.

A amplitude de variação para altura de inserção da espiga foi de 112,33 a 126,32 cm, não havendo diferença entre as lâminas $(p<0,01)$ (Tabela 4). 


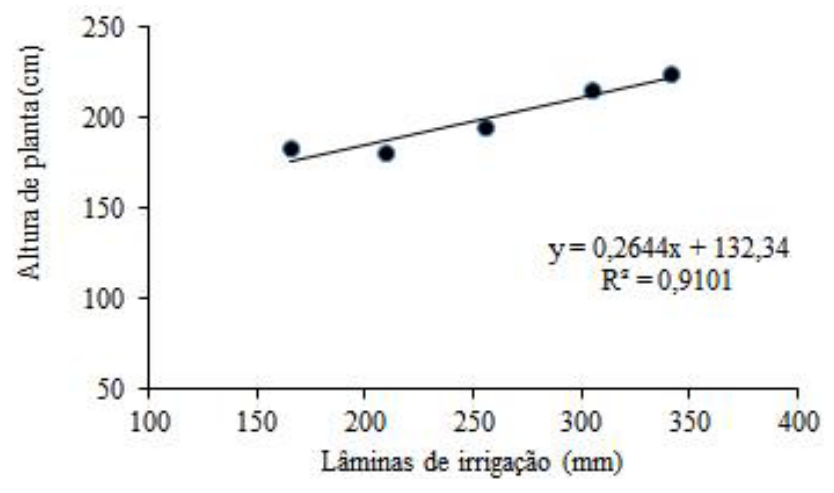

Figura 4. Altura de planta, em função de cinco diferentes lâminas de irrigação. Teresina-PI, 2010. Coeficiente da equação significativo ao nível de $1 \%$ pelo teste $\mathrm{F}$.

Tabela 4. Valores médios da altura de inserção da espiga do híbrido duplo comercial AG 1051 em função das lâminas de irrigação. Teresina-PI, 2010.

\begin{tabular}{cc}
\hline Lâminas (mm) & Altura de inserção espiga (cm) \\
\hline 340,57 & 126,32 \\
304,39 & 125,97 \\
255,32 & 124,28 \\
208,85 & 116,00 \\
165,51 & 112,33 \\
\hline
\end{tabular}

A diferenciação das lâminas, ou seja, o início do déficit hídrico, ocorreu aos 33 DAS, tempo este suficiente para o início da formação das inflorescências femininas (espigas potenciais), que segundo Ritchie et al. (2003) ocorre no estádio V5 a V6, quando a planta tem três semanas após a emergência.

Os autores ainda relatam que somente no estádio V9 as inflorescências femininas se desenvolverão a partir de cada um dos nós acima da superfície do solo, exceto os últimos seis a oito nós abaixo do pendão, o que acontece na sexta semana após a emergência. Nesse sentido, pode-se considerar que as variáveis significativas avaliadas ocorreram principalmente após a imposição dos tratamentos.

Para altura de inserção da espiga, Rocha et al. (2011) obtiveram incrementos significativos para o híbrido duplo comercial AG1051, em Teresina, no Piauí (2010). Zárate et al. (2009), em Dourados-MS, obtiveram valores de $83,9 \mathrm{~cm}$ para a maior altura de espiga e $72,9 \mathrm{~cm}$ para a menor, trabalhando com irrigação por aspersão. Esses resultados são menores do que os obtidos na presente pesquisa.

O quadrado médio dos componentes de produção do híbrido duplo comercial AG1051, em função das lâminas, o coeficiente de variação, o resíduo e a significância dos efeitos das suas respectivas análises de variância estão apresentados na Tabela 5 .

A característica comprimento médio de espiga empalhada e despalhada apresentou efeito linear $(\mathrm{p}<$ $0,05)$ com a lâmina de irrigação (Tabela 5). As variáveis DMEE, DMED, MGE, NGF, IE, RQNEHA, PEEHA e PEDHA (Tabelas 5) apresentaram $p<0,01$. A análise de variância para estas observações prova a influência das lâminas de irrigação nos seus comportamentos.

Os comprimentos de espiga empalhada e despalhada (Figura 5) apresentaram efeito linear crescente, com uma redução de $20 \%$ para espigas empalhadas e $13 \%$ para espigas despalhadas, considerando-se os tratamentos de maior e menor lâmina, o que indica a influência do déficit hídrico sobre esta variável.

Segundo Rivera-Hernández et al. (2010), o decréscimo no comprimento da espiga no estado de deficiência hídrica pode estar relacionado com a diminuição da fotossíntese.

O coeficiente angular do modelo de regressão linear descrito na Figura 5 mostra um ganho de 0,035 $\mathrm{cm}$ de comprimento das espigas empalhadas para cada milímetro de lâmina de irrigação aplicado e 0,01 cm no comprimento despalhado.

Os resultados encontrados para comprimento de espigas verdes apresentam-se dentro dos padrões para serem enquadradas como comerciais, compri- 
Tabela 5. Resumo do uso da regressão na análise de variância correspondente ao comprimento médio de espiga empalhada (CMEE), comprimento médio de espiga despalhada (CMED), diâmetro médio de espiga empalhada (DMEE), diâmetro médio de espiga despalhada (DMED), quadrado médio (a) e média de grãos por espiga (MGE), número de grãos por fileira (NGF), índice de espiga (IE), raiz quadrada do número espiga por hectare (RQNEHA), produtividade de espiga empalhada por hectare (PEEHA), e despalhada por hectare (PEDHA), quadrados médios (a) e (b) do híbrido duplo comercial AG 1051. Teresina-PI, 2010.

\begin{tabular}{|c|c|c|c|c|c|c|c|}
\hline \multicolumn{8}{|c|}{ Quadrado Médio (a) } \\
\hline FV & G.L & \multicolumn{2}{|c|}{ CMEE } & CMED & DMEE & \multicolumn{2}{|l|}{ DMED } \\
\hline $\mathbf{L}^{\prime}$ & 1 & \multicolumn{2}{|c|}{$101,183 *$} & $7,7728 *$ & $1,4295 * *$ & \multicolumn{2}{|c|}{$1,4117 * *$} \\
\hline Desv.Reg & 3 & & $0,8475^{\mathrm{ns}}$ & $0,1326^{\mathrm{ns}}$ & \multicolumn{2}{|c|}{$0,0967^{\mathrm{ns}}$} \\
\hline BL & 3 & 8,562 & & 0,5585 & 0,0931 & \multicolumn{2}{|c|}{0,1037} \\
\hline Resíduo & 10 & \multicolumn{2}{|c|}{11,9108} & 0,7853 & 0,0733 & \multicolumn{2}{|l|}{0,0895} \\
\hline \multirow[t]{2}{*}{$\mathrm{CV}(\%)$} & & \multicolumn{2}{|c|}{12,01} & 4,57 & 5,22 & \multicolumn{2}{|l|}{6,89} \\
\hline & & \multicolumn{6}{|c|}{ Quadrado Médio (b) } \\
\hline FV & G.L & MGE & NGF & IE & RQNEHA & PEEHA & PEDHA \\
\hline $\mathbf{L}^{`}$ & 1 & $47588,41 * *$ & $233,454 * *$ & $0,9989 * *$ & $34554,25^{* *}$ & $327264651,8 * *$ & $133862959,0 * *$ \\
\hline Desv.Reg & 3 & $345,484^{\mathrm{ns}}$ & $1,1301^{\mathrm{ns}}$ & $0,0372^{\mathrm{ns}}$ & $1431,72^{\mathrm{ns}}$ & $4063054,63^{\text {ns }}$ & $3052959,93^{\mathrm{ns}}$ \\
\hline BL & 3 & 1666,40 & 9,3608 & 0,00218 & 142,5403 & 1745341,1 & 232211,6 \\
\hline Resíduo & 10 & 2693,20 & 7,9826 & 0,0370 & 924,86 & 10018957,3 & 4113152,6 \\
\hline $\mathrm{CV}(\%)$ & & 10,05 & 8,51 & 39,34 & 20,77 & 39,65 & 40,85 \\
\hline
\end{tabular}

$\mathrm{ns}, *, * *$ = não significativo e significativo a $5 \%$ e $1 \%$ pelo Teste F.CV: Coeficiente de variação.

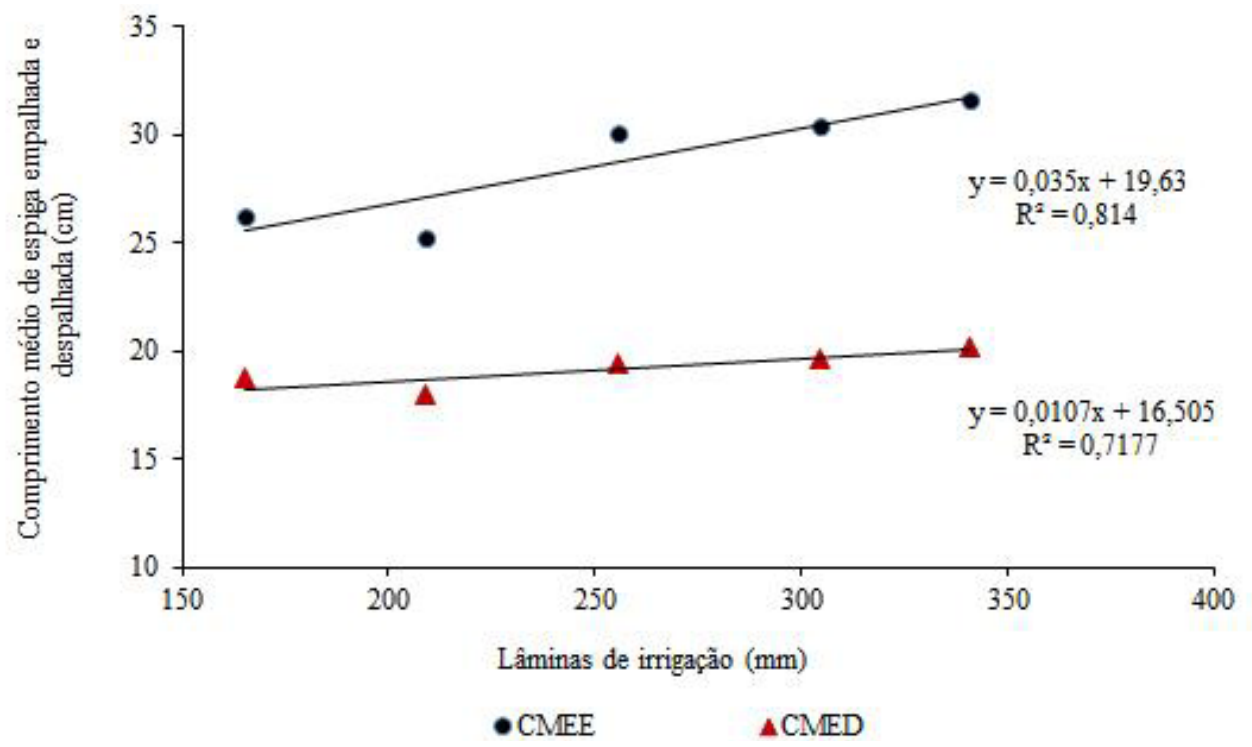

Figura 5. Comprimento médio de espiga empalhada (CMEE) e despalhada (CMED) em função de cinco diferentes lâminas de irrigação. Teresina-PI, 2010. Coeficiente da equação significativo, ao nível de 5\% pelo teste F. 
mento de $26,4 \mathrm{~cm}$ para espiga empalhada e $19,6 \mathrm{~cm}$ despalhada, na comercialização in natura no município de Teresina (Cardoso et al., 2011). Von Pinho et al. (2008), para comprimento de espiga com palha, sem a imposição de déficit hídrico, encontraram média superior a $31,0 \mathrm{~cm}$, valor este semelhante aos encontrados para os regimes hídricos de 75\%,100\% e $125 \%$ da ETo neste trabalho.

Os resultados apresentados na Tabela 5 mostram que o fator lâmina influiu $(\mathrm{p}<0,01)$ de forma linear crescente, como mostra a Figura 6, sobre o diâmetro das espigas de milho verde empalhada e despalhada, cujos valores médios variaram de 4,63 a 5,48 $\mathrm{cm}$ e de 3,82 a $4,72 \mathrm{~cm}$, respectivamente.

Efeito linear da lâmina de irrigação sobre esta variável foi observado por Biscaro et al. (2008), que obtiveram 3,7, 3,7, 3,5 e 3,4 cm para $200 \%, 100 \%$, $50 \%$ e $25 \%$ do tempo de irrigação, respectivamente. Os resultados encontrados enquadram as espigas como comerciais, que devem possuir diâmetros iguais ou superior a $3 \mathrm{~cm}$, de acordo com Albuquerque et al. (2008) e Cardoso et al. (2011).

A média de grãos por espiga e o número de grãos por fileira, características relacionadas ao desempenho produtivo, foram influenciados significativamente $(p<0,01)$ pelas lâminas de irrigação.

Observa-se na Figura 7, sobre a média do número de grãos por espiga, uma relação linear crescente, o que proporcionou um acréscimo médio de 0,831 grãos por espiga para cada milímetro de lâmina de irrigação aplicada e um $\mathrm{R}^{2}$ indicativo que $97 \%$ da variação na resposta foi explicada pela regressão.

As médias que se destacaram para esta característica foram 585,7 e 551,1 grãos, quando se aplicaram $125 \%$ da ETo e $100 \%$ da ETo, respectivamente, enquanto que a aplicação da menor lâmina resultou no valor médio de 442,08 grãos por espiga. Esses resultados indicam que as plantas podem apresentar taxas

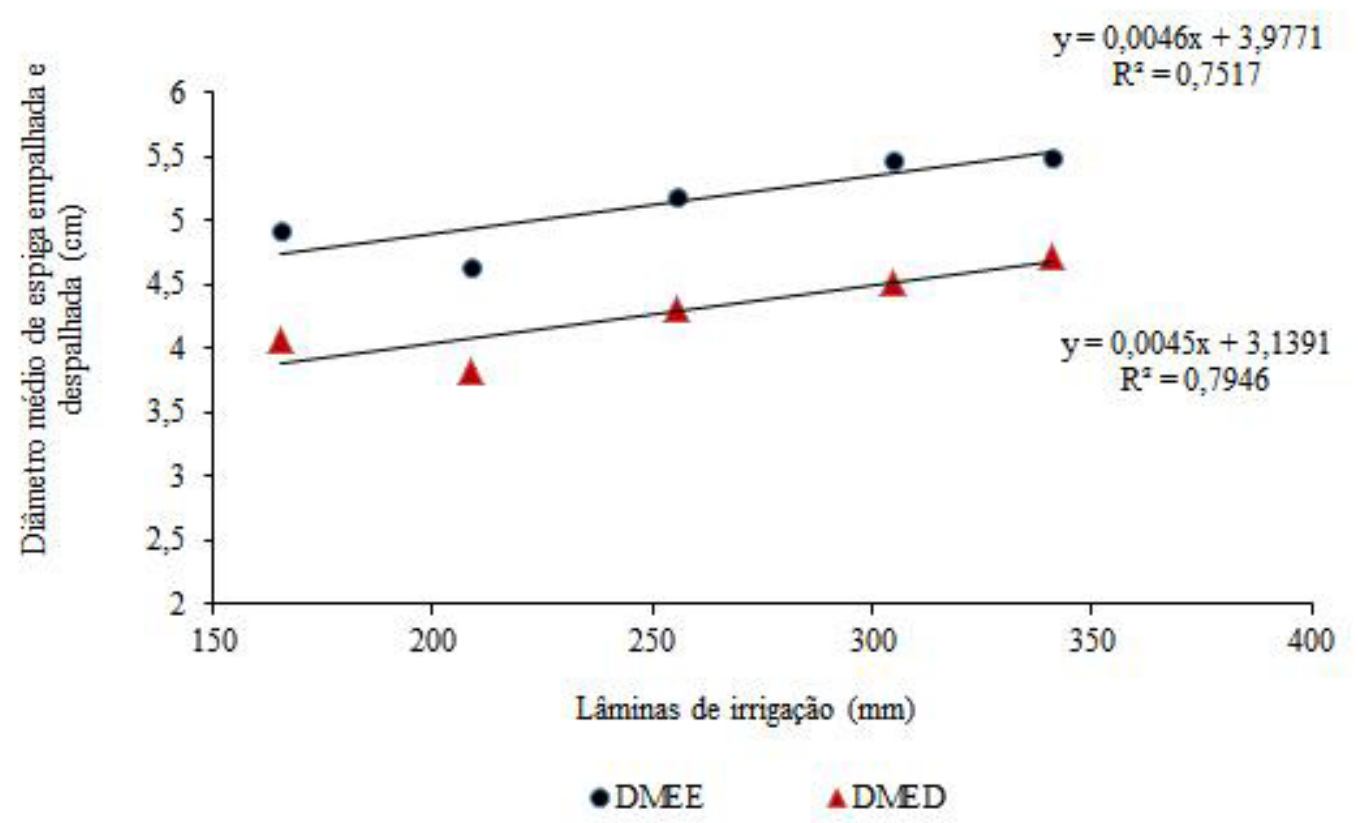

Figura 6. Diâmetro médio de espiga empalhada (DMEE) e despalhada (DMED) em função de cinco diferentes lâminas de irrigação. Teresina-PI, 2010. Coeficiente da equação significativo, ao nível de 1\% pelo teste F. 

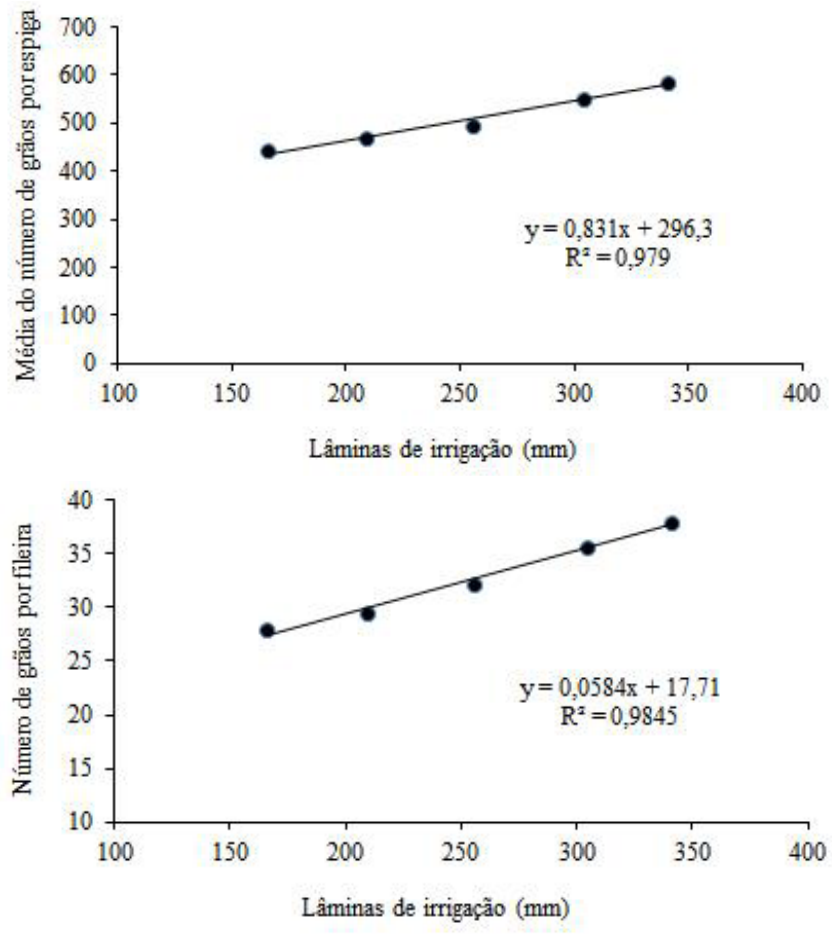

Figura 7. Média de grãos por espiga de milho verde e número de grãos por fileira, Teresina-PI, 2010. Coeficiente da equação significativo, ao nível de $1 \%$ pelo teste $\mathrm{F}$.

variáveis da média de grãos por espiga e em número de grãos por fileira, em razão de estresse abióticos (déficit hídrico), redução da área foliar, fotossíntese, partição de assimilados, ou seja, o metabolismo como um todo.

Sob condições de déficit hídrico, a emissão de inflorescência masculina causa atraso na emissão das espigas, quebrando o sincronismo entre emissão dos estigmas e liberação do pólen, justificando a falha na granação e a redução da relação grão/espiga (Bergamaschi et al., 2004).

Com $125 \%$ da ETo, os valores obtidos, foram maiores do que os encontrados por Moura et al. (2006), que obtiveram uma variação de 293,0 a 532,0 grãos por espiga, mas assemelham-se aos de Castro et al. (2013), que verificaram valores médios de 570,50,
553,90 , e 425,40 grãos por espiga para as cultivares AG2060, AG1051 e BRS2020, respectivamente.

Similarmente à característica média de grãos por espiga, o número de grãos por fileira apresentou uma resposta linear à aplicação das cinco diferentes lâminas (Figura 7), cujos valores médios variaram de 28,0 (25\% da ETo) a 37,95 (125\% da ETo).

O coeficiente angular da equação de regressão linear apresentou um acréscimo de 0,058 grãos por fileira para cada milímetro de lâmina de irrigação aplicada. E a imposição do déficit hídrico pode ter provocado o atraso no aparecimento dos estilos estigmas, reduzindo o número de grãos por fileira pela diminuição do número de óvulos polinizados. Os resultados encontrados estão próximos dos alcançados por Vieira et al. (2010), que constataram uma variação de 37,55 a 43,50 grãos por fileira.

Os dados desta pesquisa explicam que houve efeito significativo $(\mathrm{p}<0,01)$ da lâmina de irrigação sobre o índice de espiga, que respondeu de forma linear crescente e cujo maior valor foi 0,8 (Figura 8).

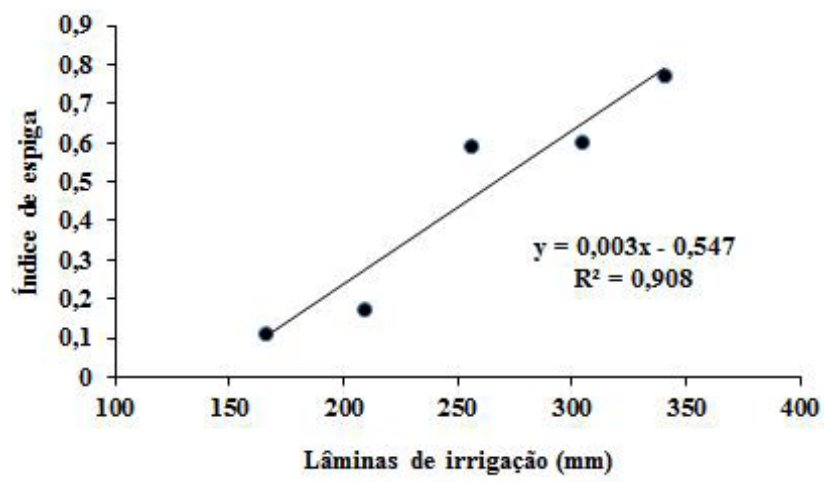

Figura 8. Índice de espiga em função das lâminas de irrigação aplicadas. Teresina-PI, 2010. Coeficiente da equação significativo, ao nível de $1 \%$ pelo teste $\mathrm{F}$.

Os menores valores 0,1 e 0,2 foram obtidos com as lâminas de $25 \%$ e $50 \%$ da ETo, respectivamente, mostrando o efeito do déficit hídrico, quan- 
do imposto entre o pré-florescimento e o enchimento de espigas. Nessa fase, a deficiência de água reduz a eficiência da polinização, seja pelo ressecamento do grão de pólen, inviabilizando-o, ou pelo aumento do intervalo entre o florescimento masculino e feminino, ocasionando a presença de plantas estéreis.

Campos et al. (2010), em cinco municípios produtores de milho safrinha no Estado do Goiás, alcançaram valores entre 0,9 e 1,0 para a cultivar CDX -98T03, por conseguinte, maiores do que o tratamento de $125 \%$ da ETo aqui encontrado.

A produtividade de espigas verdes respondeu linearmente à irrigação, alcançando $13.453,13 \mathrm{~kg} \mathrm{ha}^{-1}$ quando empalhada e $8.465,62 \mathrm{~kg} \mathrm{ha}^{-1}$ quando despalhada no tratamento de $125 \%$ da ETo. Quando aplicada a menor lâmina $165,51 \mathrm{~mm}$, a produtividade de espigas empalhadas foi $1.420,63 \mathrm{~kg} \mathrm{ha}^{-1} \mathrm{e} 1.007,92 \mathrm{~kg}$ ha $^{-1}$ para espigas despalhadas (Figura 9). Em termos percentuais, registra-se um aumento de $947 \%$ para espiga empalhada e $839 \%$ para espiga despalhada quando se compara a lâmina de $340,57 \mathrm{~mm}$ com a de $165,51 \mathrm{~mm}$.

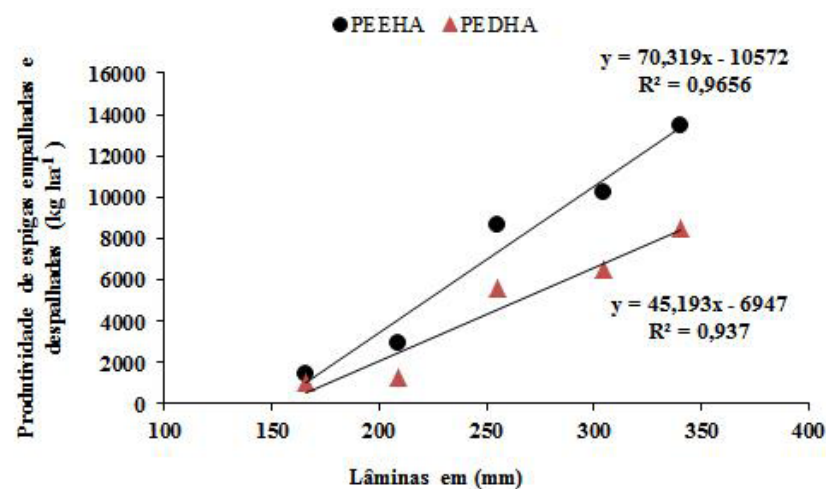

Figura 9. Produtividade de espiga empalhada e despalhada por hectare (PEEHA e PEDHA) em função lâminas de irrigação aplicadas. Teresina-PI, 2010. Coeficiente da equação significativo, ao nível de $1 \%$ pelo teste $\mathrm{F}$.
O incremento pode ser resultado do maior nível de conteúdo de água no solo, que proporciona um maior desenvolvimento foliar, consequentemente, maior produção de fotoassimilados e, portanto, maior produção de espigas da lâmina a $125 \%$ da ETo em relação à aplicação de $25 \%$ da ETo. Oktem (2008) constatou aumento progressivo na produção de espigas verdes $9.150,12.340,13.850$ e $14.720 \mathrm{~kg} \mathrm{ha}^{-1}$, em função dos tratamentos de irrigação adotados: $70 \%$, $80 \%, 90 \%$ e $100 \%$ da evaporação do tanque classe A, respectivamente.

Considera-se o aumento da produtividade de espigas verdes empalhadas, em função do acréscimo das lâminas, sendo este incremento de 51,98\% quando se aumentou a lâmina de 165,51 para $208,85 \mathrm{~mm}$; de 208,85 para $255,32 \mathrm{~mm}$ o aumento foi de $65,94 \%$; de 255,32 para $304,39 \mathrm{~mm}$ o aumento foi de $15,26 \%$ e de 304,39 a $340,57 \mathrm{~mm}$ o acréscimo foi igual a $23,78 \%$.

O coeficiente angular da regressão mostra que o acréscimo de cada $\mathrm{mm}$ de água aplicado proporciona uma adição de 70,31 kg ha-1 de espiga verde empalhada e 45,19 $\mathrm{kg} \mathrm{ha}^{-1}$ despalhada (Figura 9). Já as condições de déficit hídrico impostas nos tratamentos $25 \%$ da ETo e 50\% da ETo, aos 33 DAS, podem ter causado baixa produtividade de espigas empalhadas na condução deste experimento.

Experimento conduzido no município Ijaci-MG proporcionou valores médios de produtividade de espigas empalhadas (PEE) de 13.795,89 $\mathrm{kg} \mathrm{ha}^{-1}$, para cultivares comerciais, e de $12.265,24 \mathrm{~kg} \mathrm{ha}^{-1}$, para cultivares experimentais, segundo Albuquerque et al. (2008).

Resultados superiores foram obtidos por Albuquerque et al. (2008), no município de Lavras-MG, com as produtividades médias apresentando-se entre 21.292,69 $\mathrm{kg} \mathrm{ha}^{-1}$, para 32 híbridos experimentais, e $18.412,52 \mathrm{~kg} \mathrm{ha}^{-1}$, para quatro híbridos comerciais avaliados, merecendo destaque o híbrido duplo co- 
mercial AG 1051 com produtividade média de 22.085 $\mathrm{kg} \mathrm{ha}^{-1}$. Essas elevadas produtividades podem ser atribuídas à maior fertilidade natural do solo e às menores temperaturas do ar no município de Lavras.

A produtividade de espigas verdes despalhadas também aumentou em função do acréscimo das lâminas, sendo o incremento de 22,31\% quando se aumentou a lâmina de 165,51 para $208,85 \mathrm{~mm}$; de $76,77 \%$ quando a lâmina passou de 208,85 para $255,32 \mathrm{~mm}$; de 255,32 para $304,39 \mathrm{~mm}$ o aumento foi $14,18 \%$, e de 304,39 para $340,57 \mathrm{~mm}$ o aumento foi igual a $23,08 \%$.

O coeficiente angular da equação de regressão linear mostra que o acréscimo de cada $\mathrm{mm}$ de água aplicado proporciona uma adição de $45,19 \mathrm{~kg} \mathrm{ha}^{-1}$ de espiga verde despalhada.

Os valores médios para produção de espigas verdes despalhadas de Biscaro et al. (2008), com quatro diferentes tempos de irrigação $(25 \%, 50 \%$, $100 \%$ e $200 \%$ ) foram: $5.675,55,5.964,76,7.502,84$ e $8.779,29 \mathrm{~kg} \mathrm{ha}^{-1}$, respectivamente. Com os menores tempos de irrigação, os valores encontrados pelos autores citados apresentam-se maiores que os tratamentos do presente trabalho de $25 \%$ da ETo e de $50 \%$ da ETo, contudo, para os maiores tempos de irrigação (100\% e $200 \%)$, as produções mostram-se semelhantes aos tratamentos com irrigação de $100 \%$ da ETo e $125 \%$ da ETo.

Blanco et al. (2011) obtiveram $7.620 \mathrm{~kg} \mathrm{ha}^{-1}$ para espigas sem palha, confirmando-se menor que o resultado de Cardoso et al. (2004), que foi de 10.802 $\mathrm{kg} \mathrm{ha}^{-1}$ e próximo ao encontrado para lâmina de $125 \%$ da ETo 8.465,62 $\mathrm{kg} \mathrm{ha}^{-1}$.

\section{Conclusões}

1. A produtividade de espigas verdes responde de forma linear às lâminas de irrigação, com uma adição $70,31 \mathrm{~kg} \mathrm{ha}^{-1}$ para espiga empalhada e 45,19 $\mathrm{kg} \mathrm{ha}^{-1}$ para despalhadas, para cada mm de água aplicado.

2. Os componentes de produção diâmetro de espiga com e sem palha, comprimento de espiga com e sem palha, número de grãos por espiga, número de grãos por fileira e índice de espiga apresentam incrementos positivos com uma tendência linear crescente à aplicação das lâminas de irrigação.

\section{Referências}

ALBUQUERQUE, C. J. B.; VON PINHO, R. G.; SILVA, R. da. Produtividade de híbridos de milho verde experimentais e comerciais. Journal of Biosciense, Uberlândia, v. 24, n. 2, p. 69-76, 2008.

ALBUQUERQUE, C. J. B.; VON PINHO, R. G.; BORGES, I. D.; SOUSA FILHO, A. X. de; FIORINI, I. V. A. Desempenho de híbridos experimentais e comerciais de milho para produção de milho verde. Ciência e Agrotecnologia, Lavras, v. 32, n. 3, p. 768-775, maio/jun. 2008

DOI: $10.1590 / \mathrm{S} 1413-70542008000300010$.

ALLEN, R. G.; PEREIRA, L. S.; RAES, D.; SMITH, M. Crop evapotranspiration: guidelines for computing crop water requirements. Roma: FAO, 1998. 300 p. (FAO. Irrigation and Drainage Paper, 56).

BASTOS, E. A.; ANDRADE JÚNIOR, A. S. de. Boletim agrometeorológico de 2013 para o Município de Teresina, Piauí. Teresina: Embrapa Meio-Norte, 2014. 38 p. (Embrapa Meio-Norte. Documentos, 228).

BERGAMASCHI, H.; DALMAGO, G. A.; BERGOCI, J. I.; BIACHI, C. A. M.; MÜLLER, A. G.; COMIRAN, F.; HELCKLER, B. M. Distribuição hídrica no período crítico do milho e produção de grãos. Pesquisa Agropecuária Brasileira, Brasília, DF, v. 39, n. 9, p. 831-839, set. 2004.

DOI: $10.1590 / \mathrm{S} 0100-204 X 2004000900001$. 
BERGAMASCHI, H.; DALMAGO, G. A.; COMIRAN, F.; BERGOCI, J. I.; MÜllER, A. G.; FRANÇA, S.; SANTOS, A. O.; RANDIN, B.; BIACHI, C. A. M.; PEREIRA, P. G. Déficit hídrico e produtividade na cultura do milho. Pesquisa Agropecuária Brasileira, Brasília, DF, v. 41, n. 2, p. 243-249, 2006.

DOI: $10.1590 / \mathrm{S} 0100-204 X 2006000200008$.

BISCARO, G. A.; MAIA, S. C. M.; SILVA, T. R. B. da. Influência da aplicação de água no milho verde irrigado na região do cerrado Sul-Mato-Grossense. Agrarian, Dourados, v. 1, n. 1, p. 67-77, jul./set. 2008.

BLANCO, F. F.; CARDOSO, M. J.; FREIRE FILHO, F. R.; VElOSO, M. E. da C.; NOGUEIRA, C. C. P.; DIAS, N. da S. Milho verde e feijãocaupi cultivados em consórcio sob diferentes lâminas de irrigação e doses de fósforo. Pesquisa Agropecuária Brasileira, Brasília, DF, v. 46, n. 5, p. 523-529, maio 2011.

DOI: 10.1590/S0100-204X2011000500010.

BRITO, M. E. B.; FILHO, G. D. de A.; WANDERLEY, J. A. C.; MELO, A. S. de; COSTA, F. B. da; FERREIRA, M. G. P. Crescimento, fisiologia e produção do milho doce sob estresse hídrico. Bioscience Journal, Uberlândia, v. 29, n. 5, p. 1244-1254, 2013.

CAlOneGO, J. C.; POleto, L. C.; DOMingueS, F. N.; TIRITAN, C. S. Produtividade e crescimento de milho em diferentes arranjos de plantas. Agrarian, Dourados, v. 4, n. 12, p. 84-90, 2011.

CAMPOS, M. C. C.; SIlVA, V. A. da; CAVAlCANTE, I. H. L.; BECKMANN, M. Z. Produtividade e características agronômicas de cultivares de milho safrinha sob plantio direto no Estado de Goiás. Revista Acadêmica de Ciências Agrárias e Ambientais, Curitiba, v. 8, n. 1, p. 77-84, jan./ mar. 2010.

CARDOSO, M. J.; CARVALHO, H. W. L. de; RIBEIRO, V. Q. Avaliação preliminar de cultivares de milho para produção de espiga verde em sistema agrícola familiar. Revista Ciência Agronômica, Fortaleza, v. 35, n. 2, p. 406-409, 2004.
CARDOSO, M. J.; RIBEIRO, V. Q.; MELO, F. B. Performance de cultivares de milho-verde no município de Teresina, Piauí. Teresina: Embrapa Meio-Norte, 2011. 4 p. (Embrapa Meio-Norte. Comunicado Técnico, 227).

CASTRO, R. S. de; SILVA, P. S. L.; CARDOSO, M. J. Baby corn, green corn, and dry corn yield of corn cultivars. Horticultura Brasileira, Brasília, DF, v. 31, n. 1, p. 100105, jan./ mar. 2013.

DOI: 10.1590/S0102-05362013000100016.

DOORENBOS, J.; KASSAM, A. M. Efeito da água no rendimento das culturas. Campina Grande: UFPB, 1994. (Estudos FAO. Irrigação e Drenagem, 33).

FIGUEIREDO, M. G. de; FRIZZONE, A. J.; PITELLI, M. M.; REZENDE, R. Lâmina ótima de irrigação do feijoeiro, com restrição de água, em função do nível de aversão ao risco do produtor. Acta Scientiarum. Agronomy, Maringá, v. 30, n. 1, p. 81-87, 2008.

DOI: 10.4025/actasciagron.v30i1.1135.

FORNASIERI FILHO, D. Manual da cultura do milho. Jaboticabal: Funep, 2007. 276 p.

MOURA, E. G. de; TEXEIRA, A. P. R.; RIBEIRO, V. do S.; AGUIAR, A. das C. F.; FARIAS, M. F. Crescimento e produtividade da cultura do milho (Zea Mays .L) submetidos a vários intervalos de irrigação, na região da pré-Amazônia. Irriga, Botucatu, v. 11, n. 2, p. 169-177, abr./jun. 2006.

OKTEM, A. Effects of deficit irrigation on some yield characteristics of sweet corn. Bangladesh Journal Botany, v. 37, n. 2, p. 127-131, 2008.

DOI: $10.3329 /$ bjb.v37i2.1718.

RITCHIE, S. W.; HANWAY, J. J.; BENSON, G. O. Como a planta de milho se desenvolve. Piracicaba: POTAFOS, 2003. 20 p. (Arquivo do Agrônomo, 15).

RIVERA-HERNÁNDEZ, B.; CARRILLO-AVILA, E.; OBRADOR-OLAN, J. J.; JUAREZ-LOPEZ, J. F.; ACEVES-NAVARRO, L. A. Morphological quality of sweet corn (Zea mays L.) ears as response to soil moisture 
tension and phosphate fertilization in Campeche, Mexico. Agricultural Water Management, Amsterdam, v. 97, n. 9, p. 1365-1374, 2010. DOI: 10.1016/j.agwat.2010.04.001.

ROCHA, D. R. da; FORNASIER FILHO, D.; BARBOSA, J. C. Efeitos da densidade de plantas no rendimento comercial de espigas verdes de cultivares de milho. Horticultura Brasileira, Brasília, DF, v. 29, n. 3, p. 392-397, jul./set. 2011. DOI: $10.1590 / \mathrm{S} 0102-05362011000300023$.

SANTOS, H. G. dos; JACOMINE, P. K. T.; ANJOS, L. H. C. dos; OLIVEIRA, V. A. de; OLIVEIRA, J. B. de; COELHO, M. R.; LUMBRERAS, J. F.; CUNHA, T. J. F. (Ed.). Sistema brasileiro de classificação de solos. 2. ed. Rio de Janeiro: Embrapa Solos, 2006. 306 p.

SILVA, A. F. da; SCHONINGER, E. L.; CAIONE, G.; KUFFEL, C.; CARVALHO, M. A. de C. Produtividade de híbridos de milho em função do espaçamento e da população de plantas em sistema de plantio convencional. Revista Brasileira de Milho e Sorgo, Sete Lagoas, v. 13, n. 2, p. 162-173, 2014.

DOI: 10.18512/1980-6477/rbms.v13n2p162-173.
THORNTHWAITE, C. W.; MATHER, J. R. The water balance. New Jersey: Drexel Institute of Technology, 1955. 104 p. Publications in climatology.

VIEIRA, M. de A.; CAMARGO, M. K.; DAROS, E.; ZAGONEL, J.; KOEHLER, H. S. Cultivares de milho e população de plantas que afetam a produtividade de espigas verdes. Acta Scientiarum. Agronomy, Maringá, v. 32, n. 1, p. 81-86, 2010. DOI: 10.4025/actasciagron.v32i1.987.

VON PINHO, L. de; PAES, M. C. D.; ALMEIDA, A. C. de; COSTA, C. A. da. Qualidade de milho verde cultivado em sistemas de produção orgânico e convencional. Revista Brasileira de Milho e Sorgo, Sete Lagoas, v. 7, n. 3, p. 279-290, 2008.

DOI: 10.18512/1980-6477/rbms.v7n3p279-290.

ZÁRATE, N. A. H.; VIEIRA, M. do C.; SOUSA, T. M. de; RAMOS, D. D. Produção e renda líquida de milho verde em função da época de amontoa. Semina: Ciências Agrárias, Londrina, v. 30, n. 1, p. 95-100, jan./mar. 2009. 